\title{
Protein Synthesis and Consolidation of Memory-Related Synaptic Changes.
}

Gary Lynch ${ }^{1,2}$, Eniko A. Kramar², and Christine M. Gall ${ }^{2,3}$

${ }^{1}$ Department of Psychiatry and Human Behavior, Univ. of California, Irvine CA 92697

${ }^{2}$ Department of Anatomy and Neurobiology, University of California, Irvine CA 92697

${ }^{3}$ Department of Neurobiology and Behavior, Univ. of California, Irvine CA 92697

Running Title: Protein Synthesis and Memory Consolidation

Key words: long term potentiation, actin, synaptic plasticity, anisomycin, integrin, hippocampus

Abbreviations: ACSF, artificial cerebrospinal fluid; act- $B 1$, activated $B 1$ integrin; ANIS, anisomycin; BDNF, brain derived neurotrophic factor; bref., brefeldin A; LTP, long term potentiation; TBS, theta burst stimulation

Communicating Author: Dr. Gary Lynch, Department of Psychiatry and Human Behavior, Univ. of California, Irvine CA 9269. Email: ga.s.lynch@gmail.com 


\section{Abstract}

Although sometimes disputed, it has been assumed for several decades that new proteins synthesized following a learning event are required for consolidation of subsequent memory. Published findings and new results described here challenge this idea. Protein synthesis inhibitors did not prevent Theta Bust Stimulation (TBS) from producing extremely stable long-term potentiation (LTP) in experiments using standard hippocampal slice protocols. However, the inhibitors were effective under conditions that likely depleted protein levels prior to attempts to induce the potentiation effect. Experiments showed that induction of LTP at one input, and thus a prior episode of protein synthesis, eliminated the effects of inhibitors on potentiation of a second input even in depleted slices. These observations suggest that a primary role of translation and transcription processes initiated by learning events is to prepare neurons to support future learning. Other work has provided support for an alternative theory of consolidation. Specifically, if the synaptic changes that support memory are to endure, learning events/TBS must engage a complex set of signaling processes that reorganize and re-stabilize the spine actin cytoskeleton. This is accomplished in fast (10 min) and slow (50 min) stages with the first requiring integrin activation and the second a recovery of integrin functioning. These results align with, and provide mechanisms for, the long-held view that memories are established and consolidated over a set of temporally distinct phases. 


\section{Introduction}

For over 50 years thinking about how memories are consolidated has been dominated by the hypothesis that the learning experience must initiate the synthesis of new proteins if the memory is to persist. Early support for this idea emerged from reports that protein synthesis inhibitors delivered around the time of the learning event impaired long-term retention of memories in a variety of behavioral tasks but had little or no effect when the retention interval was brief (Davis and Squire 1984; Hernandez and Abel 2008). Although agents that prevent transcription are highly toxic, their use also led to the related idea that behaviors resulting in enduring memories signal to the nucleus to initiate expression of plasticity-related genes and their protein products (Alberini 2009; Kandel 2001; Squire and Barondes 1970)

The case for the protein synthesis hypothesis was further strengthened by evidence that:

- A learning experience can increase the expression of genes and proteins related to synaptic functioning (Gall et al. 1998; Ganguly et al. 2013; Guzowski et al. 2001; Robles et al. 2003).

- Suppression of these same genes or gene products via knock-outs or regionally targeted treatments (oligonucleotides, AAV transfection) impair retention (Guzowski et al. 2000; Minichiello et al. 1999; Nagy et al. 2006; Plath et al. 2006; Ploski et al. 2008).

- When applied locally to hippocampus or amygdala, highly selective manipulations of transcription have profound effects on long-term retention (Barrett et al. 2011; McQuown et al. 2011; Nonaka et al. 2014). 
Growing evidence that Long-Term Potentiation (LTP) is a substrate for many forms of memory prompted new investigations into the role of protein synthesis in the consolidation of learning-related synaptic plasticity. Consistent with the behavioral literature, neither protein-synthesis or transcription inhibitors impaired the initial, early phase of LTP but both caused potentiation to gradually dissipate (Frey et al. 1996; Frey et al. 1988; Frey and Morris 1997; Huang and Kandel 1994; Sacktor 2008; Tsokas et al. 2005). Evidence also emerged that the induction of LTP stimulates gene expression and translation events associated with learning (Kelleher et al. 2004; Miyashita et al. 2008; Park et al. 2006; Pevzner et al. 2012; Steward and Worley 2002; Tao et al. 1998; Tsokas et al. 2005). Moreover, manipulations of gene expression and translation produced results that accord well with the above findings (Guzowski et al. 2000; Korte et al. 1998; Minichiello 2009).

Given this large body of supporting evidence it is surprising that the protein synthesis hypothesis has not been universally accepted (Canal et al. 2007; Gold 2008a, 2008b; Routtenberg and Rekart 2005; Rudy 2008). Opposition to the idea is based on two classes of evidence. One set indicates that at least some of the memory impairments produced by protein synthesis inhibitors may be the result of their off-target effects (e.g., Canal et al., 2007; Sharma et al., 2012). Another body of results indicates that memories and LTP can indeed persist even in the face of severe inhibition of protein synthesis (Abbas 2013; Abbas et al. 2009; Abbas et al. 2011; Abraham and Williams 2008; Fonseca et al. 2006b; Martinez et al. 1981; Pang et al. 2004; Staubli et al. 1985; Villers et al. 2012). 
The second data set is cause for concern because it not only challenges the central argument, it questions the relevance of the well-documented findings that both behavior and LTP-inducing stimulation induce changes in gene expression (Alberini 2009; Bramham and Messaoudi 2005; Chen et al. 2010; Guzowski et al. 2001; Taubenfeld et al. 2001). If neither long term memories nor LTP depend on the generation of new proteins induced by the initiating events, then what is the function of activity-regulated changes in gene and protein expression? Moreover, if memory consolidation does not depend on the initiation of new protein synthesis, then what events are critical for consolidation?

The present paper addresses the above issues. We report evidence that reinforces the conclusion that the consolidation of LTP is not blocked by protein synthesis inhibition, then describe circumstances in which the inhibitors are effective, and finally demonstrate that multiple LTP events obviate the negative actions of the inhibitors when such are present. These observations help explain some of the discrepant results in the literature and lead to the conclusion that induced synthesis is not, under normal circumstances, important to current encoding but instead paves the way for future memory formation. We also review studies demonstrating that early and delayed phases of LTP and memory consolidation dependent upon activation and subsequent recovery of signaling by integrin-class adhesion proteins, respectively, and that these events are protein synthesis independent. A final section will attempt to integrate the hypothesis that temporally distinct stages of integrin-driven cytoskeletal reorganization underly multiple stages of memory consolidation with evidence that learning and LTP induction trigger the production of proteins necessary for long term storage. 


\section{Reorganizing the Spine Actin Cytoskeleton is a Consolidating Event}

Our interest in the contribution of newly synthesized proteins to the consolidation of LTP emerged from research directed at understanding mechanisms that regulate the dendritic spine actin cytoskeleton and, thus, spine morphology. Results from our laboratories and elsewhere (Fukazawa et al. 2003; Kramar et al. 2006; Krucker et al. 2000; Lin et al. 2005a; Okamoto et al. 2009; Wang et al. 2008) led to the conclusion that the enlargement and stabilization of the spine actin cytoskeleton initiated by Theta Burst Simulation (TBS) may be a critical consolidating event. Specifically, potentiation induced with either TBS or high frequency stimulation elicits, and depends upon, new actin polymerization in dendritic spines (Fig. 1). Further analyses demonstrated that these structural events are driven by separate signaling streams that control the assembly (polymerization) and subsequent stabilization of the new actin filaments (Chen et al. 2007; Fedulov et al. 2007; Kramar et al. 2006; Mantzur et al. 2009; Rehberg et al. 2010; Rex et al. 2009; Rex et al. 2010). Integrins, a group of transmembrane adhesion receptors that regulate the cytoskeleton at most types of cellular junctions (Brakebusch and Fassler, 2003), play a central role in these processes, as indicated by results of studies using toxins, small peptides, neutralizing antibodies, or genomic manipulations (Kramar et al, 2006; Nagy et al., 2006; Wang et al., 2008). Downstream intracellular signaling cascades (small GTPases and their effectors) initiated by integrins have also been linked to LTP stabilization (Rex et al., 2009). Notably, these processes are modulated by receptors for estrogen, adenosine, and the neurotrophin BDNF (Lynch et al. 2013). Such findings suggest that reorganization and stabilization of the spine actin cytoskeleton is 
critical for the consolidation of LTP and memory, and behavioral studies have supported this conclusion (Lamprecht 2011; Mantzur et al. 2009; Rex et al. 2010). A complementary set of findings revealed that the actin cytoskeleton is stabilized within a few minutes of TBS. In particular, treatments that disrupt the generation or stabilization of new Factin prevent LTP consolidation if administered prior to or soon after TBS have no effect on potentiation (or the remodeled spine actin network) when applied 15 minutes later (Rex et al. 2007; Rex et al. 2009; Rex et al. 2010). These results identified lasting changes to the spine actin cytoskeleton as a critical step for long term expression of LTP. Note, however, that these changes occur within 2-5 minutes and thus are likely too rapid to depend on the synthesis of new protein.

Insert Figure 1 here

\section{Protein Synthesis Inhibition Fails to Disrupt LTP}

Although early actin remodeling is not likely to depend on new synthesis, it is possible that the maintenance of potentiation requires proteins that are generated following TBS. We describe here results of studies evaluating this possibility using the same hippocampal slice protocols employed in the actin studies. Specifically using adult rat hippocampal slices in an interface recording chamber, the synthesis inhibitors anisomycin $(40 \mu \mathrm{M})$ or emetine $(20 \mu \mathrm{M})$ were infused for 30 minutes before and 30 minutes after TBS; this schedule blocked incorporation of ${ }^{35} \mathrm{~S}$-methionine, bath applied at 2 $\mu \mathrm{Ci} / \mathrm{ml}$ as per Raymond et al. (2000), into protein by $88 \%$ (anisomycin) or $70 \%$ (emetine). However, neither compound detectably affected LTP: Initial potentiation, subse- 
quent decay, and the degree of stable potentiation as assessed 30-40 min after TBS were about the same when induction occurred in the presence of the inhibitors as they were when LTP was induced more than hour of after washout (Fig 2A,B). Moreover, LTP produced in the presence of anisomycin was stable for the remaining three hours of recording; there was no suggestion in the results for a late, protein synthesis dependent phase of LTP. These experiments point to the conclusion that structural changes generated in the minutes after induction are sufficient to produce long lasting potentiation and appear not to require newly translated proteins for their maintenance.

Insert Figure 2 Here

These results and other recent reports (Abbas 2013; Abbas et al. 2009; Villers et al. 2012) are at odds with many published studies showing that enduring LTP was blocked by protein synthesis inhibitors (Fonseca et al. 2006a; Frey et al. 1988; Osten et al. 1996; Tsokas et al. 2005). Thus, we conducted additional experiments to determine potential sources for the discrepancy. One possibility is that the state of the slice preparation at the time of the experiment is a critical variable. In some studies where protein synthesis inhibition impaired LTP, slices had been incubated in ACSF for several hours before the induction of LTP (Redondo et al. 2010; Sajikumar et al. 2007). Our slices were tested 2 hours after preparation.

We therefore repeated the experiments using slices that had been maintained in the recording chamber for 5 hours prior to the start of the experiment proper. Only cases in which baseline responses were stable throughout the prolonged interval prior 
to TBS were used. As shown in Figure 3A, anisomycin had no effect on baseline responses (control path) but did block the induction of stable LTP in response to a single train of TBS. Note that LTP induced in a separate pathway more than four hours earlier was unaffected by anisomycin infusion (Fig 3A, control path), a result which relates to the idea that delayed transcriptional events produce proteins needed for the maintenance of the potentiated state. The potency of the inhibitor in these longer standing preparations could not be attributed to a general decline in the viability of the slice or its capacity to maintain LTP because, as shown in a separate set of untreated slices, potentiation maintained in drug free ACSF for 6 hours is robust and stable (Fig. 3B).

Insert Figure 3 Here

\subsection{Incubation Time Determines the Effect of Protein Synthesis inhibitors.}

Why should incubation time have such a dramatic effect on the efficacy of synthesis inhibitors? One possibility is suggested by evidence that the preparation of the slice causes transient increases in the activity of kinases involved in synaptic plasticity (Ho et al. 2004) followed by a return to conditions closer to those found in vivo. In parallel there is surge in the expression of transcriptional regulators (Taubenfeld et al. 2002; Zhou et al. 1995) and synaptic proteins. Thus, it is possible that at least some of the proteins necessary for consolidation are present at supra normal levels in freshly prepared slices, thereby creating an artificial condition in which inhibitors are ineffective. This argument predicts that slices incubated in protein synthesis inhibitors from the time of sectioning through the delivery of theta bursts will not exhibit LTP. The results did not 
support this hypothesis: slices incubated with anisomycin from cutting through testing exhibited normal and stable LTP (Fig 4).

Insert Figure 4 here

This outcome implies that the ability to sustain LTP in the face of synthesis inhibition is not due to proteins generated in response to preparation of the slices. Instead, it appears that the relevant proteins are already present, which suggests an alternative explanation for the time-dependent actions of protein synthesis inhibition. It is possible that levels of memory-related proteins decrease with incubation time, reflecting their normal half lives and ongoing proteolytic activity. Under these depleted conditions, TBS could initiate changes in the actin cytoskeleton needed for rapid consolidation and perhaps also initiate the synthesis of proteins needed to sustain the potentiated state (Kelly et al. 2007; Ramachandran and Frey 2009). To be clear, according to this account, relevant proteins are depleted during a prolonged incubation of slices creating a condition in which the production of enduring LTP will depend on proteins synthesized in response to afferent stimulation. So, blocking protein synthesis at the time of TBS will prevent LTP from enduring.

One way to test this hypothesis is to use a variation of the protocol Frey and Morris (1997) developed to test their synaptic tag and capture hypothesis. The basic conclusion from their experiments was that weakly stimulated synapses that normally would not sustain LTP might capture proteins generated by earlier strong stimulation applied 
to other synapses on the same neuron. By doing so the weakly stimulated synapses would now express enduring LTP.

In this experiment we first incubated the slices for the duration needed to deplete the relevant proteins, creating a preparation in which anisomycin would normally prevent enduring LTP. We then applied TBS to one pathway with the intent of generating a new supply of relevant proteins; 45 minutes after this event, anisomycin was infused to prevent further protein synthesis that might be produced when a second TBS train was applied to a second input. Thus, if the second train of TBS produced stable LTP then it would have to have been supported by proteins generated by the first round of TBS.

As show in Figure 5, persistent LTP was established in the second pathway despite the presence of the protein synthesis inhibitor. These results support the motivating hypothesis and the argument that, in acute slice preparations, long incubations deplete proteins needed for LTP consolidation, making it necessary for the TBS train to replenish the pool in order to generate lasting potentiation.

Insert Figure 5 here

It is worth noting that conceptually the above experiment is identical to that reported in Figure 3. Yet the outcomes were quite different. As shown in Figure 3, the first TBS train did not protect LTP produced by the second train from the effect of anisomycin, whereas in Figure 5 it did. There is, however, one important difference between the two studies: the interval separating the two TBS trains was over 5 hours in the first experiment (Figure 3) but less than 60 minutes in the second (Figure 5). Thus, consistent 
with experimental results reported by Frey and Morris (1997), one could have predicted these results from the intervals described by Frey and Morris as producing their tagging effect. In any event, the long delay in our experiments presumably provided sufficient time for degradation of the proteins generated by the first TBS episode.

\subsection{Summary of Protein Synthesis Inhibition Results}

Experiments described above have identified one potential source of the conflict between researchers examining the role of protein synthesis in LTP -- the state of the slice at the time of LTP-inducing stimulation. Incubating slices for several hours prior to the induction of LTP depletes the pool of proteins that normally support the consolidation of potentiation and thereby create a condition in which induced synthesis is necessary to support new potentiation. Note that it is not unlikely that rate of depletion varies between different types of slice preparations: it may well be the case that several hours are not be needed in some circumstances to instate a need for induced synthesis to maintain potentiation. Regarding this point, it would be instructive to measure the rate of breakdown for rapidly induced synaptic proteins likely to be involved in stabilizing the potentiated state.

Based on his recent experiments, Abbas (2013, p301) reached the conclusion that '... these results favor the notion that constitutive rather than triggered protein synthesis is important for LTP stabilization'. There remains, however, the possibility that constitutive synthesis is not sufficient; it could be the case that production of memory related proteins only occurs after LTP/learning episodes. This point is intriguing because it suggests that continuous learning, as undoubtedly happens in real world envi- 
ronments, not only encodes new information but is also required for the acquisition of future memories. It will be of interest in this regard to test if patterns of afferent stimulation that do not produce LTP (input 1) are as effective as TBS in preventing synthesis inhibitors from blocking LTP consolidation (input 2) in slices that have been maintained for several hours. In other words, is normal activity in brain networks sufficient to produce LTP-related proteins or are these only generated by discrete learning events?

\section{Integrins Support a Late Stage of Consolidation}

While our experiments do not support for the argument that new protein synthesis is required for consolidation outside of special circumstances, other work has suggested in an alternative explanation for both rapid and delayed stages of consolidation. Specifically, we find that TBS must engage an elaborate collection of signaling events leading to reorganization of the spine actin cytoskeleton in order to shift synapses into a stable potentiated state (Lynch et al. 2013; Lynch et al. 2007). Disrupting any of several key steps in these parallel signaling streams has no effect on the induction and initial expression of LTP but blocks its stabilization. It takes only 1-2 minutes to mobilize the cascades which then rapidly dissipate although elevated levels of filamentous (F) actin

remains (Babayan et al. 2012; Rex et al. 2009; Rex et al. 2010). These results are consistent with the long-held view that memories are constructed in stages (Davis and Squire 1984; James 1890; McGaugh 2000). In the first stage, the memory trace is generated (initial expression); this does that depend on reorganization of the cytoskeleton. The later consolidating stage then requires stabilization of an expanded actin cytoskeleton. 
We now describe experiments that uncovered a novel, delayed stage in the consolidation process (Babayan et al. 2012). This unexpected phenomenon was identified during recent analyses of integrins, synaptic membrane receptors that play a central role in the rapid phase of consolidation. We had previously shown that integrins containing the $ß 1$ subunit are required for TBS-induced increases in spine F-actin and the expression of stable LTP. We then turned to the question of whether intermittent synaptic activity could essentially sustain $ß 1$ integrins in the activated conformation (as detected using state-specific antisera and immunostaining). Specifically, after initially establishing that an initial round of TBS activated synaptic integrins and generated LTP, we attempted to reactivate the $ß 1$ integrins by presenting a second TBS train (TBS2) to the same axons 10-to-40 minutes later. The results were surprising: the second TBS train did not re-activate integrins or their downstream actin management pathways. However, integrin activation was achieved when the interval separating the two TBS episodes was stretched to $50-60$ minutes. Thus, there is an apparent refractory period of about 50 minutes during which a second TBS train cannot stimulate the synaptic integrins that are critical to structural remodeling and LTP (Chun et al. 2001; Huang et al. 2006; Kramar et al. 2006).

We then asked if the subsequent recovery of integrin reactivity was functionally significant to the maintenance of LTP (Babayan et al. 2012). To do this we infused function blocking $ß 1$ integrin antisera prior to the recovery of integrin function (30 minutes post-TBS). Thus, if recovery of integrin reactivity is important to LTP it should be revealed by this treatment. Remarkably, neutralizing $B 1$ antisera infusion produced a rapid and complete elimination of LTP that had already passed through the first consoli- 
dation stage (Fig 6B). However, this same antisera had no effect on the maintenance of LTP when it was infused after the refractory period, at 60 minutes post-TBS (Fig 6C). Based on these results we conclude that integrin receptors not only contribute to an initial consolidation phase but upon re-entering the reactive stage contribute to a second consolidating phase.

Insert Figure 6 Here

We then investigated the source of the integrin-refractory period. We suspected that this could be due to either to (a) internalization of the receptors or (b) their degradation and replacement with new copies. The degradation hypothesis is consistent with evidence that theta bursts activate calpain (Vanderklish et al. 1995; Vanderklish et al. 2000), a calcium dependent protease that is found in spines (Perlmutter et al. 1988) and known to cleave synaptic integrins (Huttenlocher et al. 1997). To test the replacement hypothesis we used brefeldin A, a fungal antibiotic that prevents new surface expression (i.e., plasma membrane insertion) of integrins in slices (Lin et al. 2005b). In adult hippocampal slices a 40-minute brefeldin A treatment prior to a single TBS train (when responsive integrins are in place) had no effect on integrin activation but it blocked integrin reactivation by a second TBS delivered 60 minutes later (Fig 6E). Moreover, brefeldin A reversed LTP (Fig 6F) when infused after induction in the manner seen with infusion of $B 1$ integrin neutralizing antisera (Fig 6N).

The time course for receptor replacement via membrane insertion fits well with the delayed packaging and transport of select proteins from the Golgi apparatus (Lin et 
al., 2005b). This implies that the replacement function draws on existing pools of integrins to end the refractory period. However, it is also possible that recovery depends on the synthesis of new integrins. If this were the case then applying anisomycin beginning 40 minutes before a second TBS train should prevent integrin reactivation with that stimulation applied at 60 minutes. However, blocking protein synthesis did not interfere with integrin reactivation. Thus, the protein synthesis hypothesis again gains no support, and it is reasonable to infer that the refractory period ends as already existing integrins enter the synapse to replace degraded ones.

The discovery that LTP requires a second stage of integrin-dependent consolidation motivated us to determine if integrin activity also makes a delayed contribution to the maintenance of an established memory. To test this idea we trained mice in an object location memory task. They were given 10 minute exposures to two identical objects placed at fixed locations in an open arena; 24 hours later they were returned to the arena containing same objects but with one object moved to a novel location. As expected, during the retention test the mice spend greater time exploring the displaced object, indicating they remembered the original location (Babayan et al. 2012). Longterm object location memory is dependent on neurons in the CA1 field of rostral hippocampus (Barrett et al. 2011), the same region studied in the above hippocampal slice experiments. Thus, we determined if infusions of $ß 1$ integrin neutralizing antisera into rostral CA1 would impair retention. When delivered 5 or 20 minutes after object location memory training, retention 24 hours later was substantially impaired. Yet, when the neutralizing antisera was infused 60 minutes after training (after the integrin refractory period) the antisera had no effect of retention (Fig 6D) (Babayan et al. 2012). The close 
correspondence between the outcomes of the LTP and behavioral experiments strongly suggest that $ß 1$ integrins are supporting delayed stabilization in both cases.

\subsection{Summary}

Our previous research revealed that TBS activates a set of signaling events that consolidated the synaptic changes supporting LTP by rapidly remodeling and restabilizing the spine actin cytoskeleton. The experiments just described indicate that although these initial events are necessary for consolidation they are not sufficient. There is a later phase of integrin-dependent activity, which depends on processes that replace the likely degraded integrins that supported the initial consolidating events. It is important to emphasize that neither of these consolidation stages require new proteins to be generated by TBS.

It is not clear why the creation of a stable actin cytoskeleton requires two stages of integrin activity. However, one might speculate that during the first stage the adhesion receptors generate new actin networks and, via cross linking and capping, render them resistant to disruption. Notably, the actin depolymerizing protein cofilin is inactivated for about 10 minutes after TBS but then returns to its dephosphorylated, constitutively active configuration. There is therefore enough time to generate and stabilize the networks before the return of cofilin activity. Note however, that the synaptic integrins driving these events will no longer be signaling from about 10 minutes forward; it will not be possible during this period to anchor the reorganized cytoskeleton to the extracellular matrix. The return of functional integrins at 50-60 minutes post-TBS could thus produce 
the matrix-cytoskeletal linkages that underlie the extreme stability of cell junctions and, in the present case, the changes to spine and synapse morphology that maintain LTP.

\section{Discussion}

Both clinical and experimental evidence indicate that memories become more resistant to disruption as they age (McGaugh 2003; Ribot 1882). The term 'consolidation' emerged over 100 years ago to explain why new memories are especially vulnerable to interference (Muller and Pilzecker 1900) -- the reason is that the memory trace requires time to consolidate (see McGaugh, 2003, for a historical context). For several decades the idea that memory consolidation depends on new proteins synthesized in response to the learning event has dominated thinking about this problem. Even though there have always been skeptics, the modern literature contains dozens of reports of studies using protein synthesis inhibitors that provide support for this idea. Perhaps one reason why the protein synthesis hypothesis has continued to prevail is that no strong alternative explanation of how memories are consolidated has emerged.

The data assembled here should be considered in this context. First, our LTP experiments do not support for the protein synthesis hypothesis. We do not stand alone on this matter (Abbas 2013; Abbas et al. 2009; Abbas et al. 2011; Pang et al. 2004; Villers et al. 2012). However, it is important to note that we do not simply report that inhibiting protein synthesis failed to prevent the lasting form of LTP. Our experiments also provide insights into the conditions that determine when protein synthesis inhibition will produce impairment. Specifically, we argue that this can occur when the level of the 
relevant existing proteins is low. In this case TBS stimulation has to induce the synthesis of new proteins if LTP is to endure.

If the synthesis of new protein is not required to consolidate memories then what processes are critical? Our research provides a basis for offering a strong alternative explanation. Specifically, it revealed that critical consolidating processes include intracellular signaling events orchestrated by surface receptors belonging to transmitter (NMDA), modulatory (e.g., BDNF, adenosine), and adhesion (integrins) classes. Ultimately, these events produce recognizable changes to the substructures responsible for the anatomy of spines and their synapses. These actin-regulating processes operate in two stages. The first is completed in about 10 minutes while the second takes about 50 minutes. Neither stage is dependent upon TBS generating new proteins.

It is undeniable that the behavioral experiences that create memories, and the TBS that induces LTP, initiate signaling that produces proteins relevant to memory. Thus, it is important to address the significance of these results in the context of our findings. We reiterate that our experiments support the ideas that induced synthesis is only required when the supply of key proteins has been reduced and that replenishment can be had with earlier induction of LTP. Consider these observations in the context of an animal operating in a real world environment. Inputs that would initiate the synaptic events that support LTP and memory are surely occurring multiple times a minute, activities that would produce a constant supply of the synaptic proteins needed to support memory. But exceptions could occur: One could imagine circumstances both in everyday life and in the laboratory that lead to a depletion of the relevant proteins. Very little is known about how laboratory-housing conditions influence the basal level of memory- 
relevant proteins but it seems obvious that they constitute a kind of deprivation. Hence we predict that environmental enrichment during the hours preceding a training trial will greatly reduce the dependency of memories on induced synthesis. We should perhaps also be concerned with variability in protein availability due to the circadian regulation of transcription factors (Luo et al. 2013); might the influence of synthesis inhibitors on LTP and memory consolidation be dependent on when animals or slices are tested? The list of factors that may result in low levels of memory related proteins, and so relate to contradictory results with inhibitors, could go on. But the essence of our argument is simply this: encoding of new information via synaptic changes under what are likely normal conditions (prior learning or, its slice equivalent, prior LTP) does not require induced synthesis. We interpret the work on induced transcription and translation not in terms of how specific memories are formed but as an effort that led to discovery of 'memory proteins' that must be available if storage is to occur. By any measure, identification of these constitutes a major advance. As a substitute for the de novo synthesis hypothesis, we propose a three stage model: (a) formation of a trace, due to rapid accumulation of transmitter receptors, followed by (b) fast and delayed consolidation stages reflecting changes in the substructure governing architecture of synapses.

Acknowledgements: This research was supported in part by NINDS grants NS45260 and 485110-24614 to G.L. and C.M.G., and National Science Foundation Grant \#1146708 to G.L. The authors are grateful for reviewer suggestions for extensive revisions to the manuscript. 


\section{References}

Abbas A.K., 2013. Evidence for constitutive protein synthesis in hippocampal LTP stabilization. Neuroscience. 246, 301-311.

Abbas A.K., Dozmorov M., Li R., Huang F.S., Hellberg F., Danielson J., Tian Y., Ekstrom J., Sandberg M., Wigstrom H., 2009. Persistent LTP without triggered protein synthesis. Neurosci Res. 63, 59-65.

Abbas A.K., Huang F.S., Li R., Ekstrom J., Wigstrom H., 2011. Emetine treatment masks initial LTP without affecting long-term stability. Brain Res. 1426, 18-29.

Abraham W.C., Williams J.M., 2008. LTP maintenance and its protein synthesis-dependence. Neurobiol Learn Mem. 89, 260-268.

Alberini C.M., 2009. Transcription factors in long-term memory and synaptic plasticity. Physiol Rev. 89, 121-145.

Babayan A.H., Kramar E.A., Barrett R.M., Jafari M., Haettig J., Chen L.Y., Rex C.S., Lauterborn J.C., Wood M.A., Gall C.M., Lynch G., 2012. Integrin dynamics produce a delayed stage of long-term potentiation and memory consolidation. J Neurosci. 32, 12854-12861.

Barrett R.M., Malvaez M., Kramar E., Matheos D.P., Arrizon A., Cabrera S.M., Lynch G., Greene R.W., Wood M.A., 2011. Hippocampal focal knockout of CBP affects specific histone modifications, long-term potentiation, and long-term memory. Neuropsychopharmacology. 36, 1545-1556.

Baudry M., Kramar E., Xu X., Zadran H., Moreno S., Lynch G., Gall C., Bi X., 2012. Ampakines promote spine actin polymerization, long-term potentiation, and learning in a mouse model of Angelman syndrome. Neurobiol Dis. 47, 210-215.

Brakebusch C., Fassler R., 2003. The integrin-actin connection, an eternal love affair. Embo J. 22, 2324-2333.

Bramham C., Messaoudi E., 2005. BDNF function in adult synaptic plasticity: the synaptic consolidation hypothesis. Prog Neurobiol. 76, 99-125. 
Canal C.E., Chang Q., Gold P.E., 2007. Amnesia produced by altered release of neurotransmitters after intra amygdala injections of a protein synthesis inhibitor. Proc Natl Acad Sci U S A. $104,12500-12505$.

Chen L.Y., Rex C.S., Casale M.S., Gall C.M., Lynch G., 2007. Changes in synaptic morphology accompany actin signaling during LTP. J Neurosci. 27, 5363-5372.

Chen L.Y., Rex C.S., Sanaiha Y., Lynch G., Gall C.M., 2010. Learning induces neurotrophin signaling at hippocampal synapses. Proc Natl Acad Sci U S A. 107, 7030-7035.

Chun D., Gall C.M., Bi X., Lynch G., 2001. Evidence that integrins contribute to multiple stages in the consolidation of long term potentiation. Neuroscience. 105, 815-829.

Davis H.P., Squire L.R., 1984. Protein synthesis and memory: a review. Psychol Bull. 96, 518559.

Fedulov V., Rex C.S., Simmons D.A., Palmer L., Gall C.M., Lynch G., 2007. Evidence that longterm potentiation occurs within individual hippocampal synapses during learning. J Neurosci. 27, 8031-8039.

Fonseca R., Nagerl U.V., Bonhoeffer T., 2006a. Neuronal activity determines the protein synthesis dependence of long-term potentiation. Nat Neurosci. 9, 478-480.

Fonseca R., Vabulas R.M., Hartl F.U., Bonhoeffer T., Nagerl U.V., 2006b. A balance of protein synthesis and proteasome-dependent degradation determines the maintenance of LTP. Neuron. 52, 239-245.

Frey U., Frey S., Schollmeier F., Krug M., 1996. Influence of actinomycin D, a RNA synthesis inhibitor, on long-term potentiation in rat hippocampal neurons in vivo and in vitro. J. Physiol. 490, 703-711.

Frey U., Krug M., Reymann K.G., Matthies H., 1988. Anisomycin, an inhibitor of protein synthesis, blocks late phases of LTP phenomena in the hippocampal CA1 region in vitro. Brain Res. 452, 57-65.

Frey U., Morris R.G., 1997. Synaptic tagging and long-term potentiation. Nature. 385, 533-536. 
Fukazawa Y., Saitoh Y., Ozawa F., Ohta Y., Mizuno K., Inokuchi K., 2003. Hippocampal LTP is accompanied by enhanced $\mathrm{F}$-actin content within the dendritic spine that is essential for late LTP maintenance in vivo. Neuron. 38, 447-460.

Gall C.M., Hess U.S., Lynch G., 1998. Mapping brain networks engaged by, and changed by, learning. Neurobiol Learn Mem. 70, 14-36.

Ganguly K., Rejmak E., Mikosz M., Nikolaev E., Knapska E. , Kaczmarek L., 2013. Matrix metalloproteinase (MMP) 9 transcription in mouse brain induced by fear learning. J Biol Chem. 288, 20978-20991.

Gold P.E., 2008a. Protein synthesis and memory. Introduction. Neurobiol Learn Mem. 89, 199200.

Gold P.E., 2008b. Protein synthesis inhibition and memory: formation vs amnesia. Neurobiol Learn Mem. 89, 201-211.

Guzowski J.F., Lyford G.L., Stevenson G.D., Houston F.P., McGaugh J.L., Worley P.F., Barnes C.A., 2000. Inhibition of activity-dependent arc protein expression in the rat hippocampus impairs the maintenance of long-term potentiation and the consolidation of long-term memory. J Neurosci. 20, 3993-4001.

Guzowski J.F., Setlow B., Wagner E.K., McGaugh J.L., 2001. Experience-dependent gene expression in the rat hippocampus after spatial learning: a comparison of the immediateearly genes Arc, c-fos, and zif268. J Neurosci. 21, 5089-5098.

Hernandez P.J., Abel T., 2008. The role of protein synthesis in memory consolidation: progress amid decades of debate. Neurobiol Learn Mem. 89, 293-311.

Ho O.H., Delgado J.Y., O'Dell T.J., 2004. Phosphorylation of proteins involved in activitydependent forms of synaptic plasticity is altered in hippocampal slices maintained in vitro. J Neurochem. 91, 1344-1357.

Huang Y.Y., Kandel E.R., 1994. Recruitment of long-lasting and protein kinase A-dependent long-term potentiation in the CA1 region of hippocampus requires repeated tetanization. Learn Mem. 1, 74-82. 
Huang Z., Shimazu K., Woo N.H., Zang K., Muller U., Lu B., Reichardt L.F., 2006. Distinct roles of the beta 1-class integrins at the developing and the mature hippocampal excitatory synapse. J Neurosci. 26, 11208-11219.

Huttenlocher A., Palecek S.P., Lu Q., Zhang W., Mellgren R.L., Lauffenburger D.A., Ginsberg M.H., Horwitz A.F., 1997. Regulation of cell migration by the calcium-dependent protease calpain. J. Biol. Chem. 272, 32719-32722.

James W. (1890). Principles of Psychology. Holt, New York.

Kandel E.R., 2001. The molecular biology of memory storage: a dialogue between genes and synapses. Science. 294, 1030-1038.

Kelleher R.J., 3rd, Govindarajan A., Tonegawa S., 2004. Translational regulatory mechanisms in persistent forms of synaptic plasticity. Neuron. 44, 59-73.

Kelly M.T., Yao Y., Sondhi R., Sacktor T.C., 2007. Actin polymerization regulates the synthesis of PKMzeta in LTP. Neuropharmacol. 52, 41-45.

Korte M., Kang H., Bonhoeffer T., Schuman E., 1998. A role for BDNF in the late-phase of hippocampal long-term potentiation. Neuropharmacol. 37, 553-559.

Kramar E.A., Babayan A.H., Gavin C.F., Cox C.D., Jafari M., Gall C.M., Rumbaugh G., Lynch G., 2012. Synaptic evidence for the efficacy of spaced learning. Proc Natl Acad Sci U S A. $109,5121-5126$.

Kramar E.A., Lin B., Rex C.S., Gall C.M., Lynch G., 2006. Integrin-driven actin polymerization consolidates long-term potentiation. Proc Natl Acad Sci U S A. 103, 5579-5584.

Krucker T., Siggins G.R., Halpain S., 2000. Dynamic actin filaments are required for stable longterm potentiation (LTP) in area CA1 of the hippocampus. Proc. Natl. Acad. Sci. USA. 97, 6856-6861.

Lamprecht R., 2011. The roles of the actin cytoskeleton in fear memory formation. Front Behav Neurosci. 5, 39.

Lin B., Kramar E.A., Bi X., Brucher F.A., Gall C.M., Lynch G., 2005a. Theta stimulation polymerizes actin in dendritic spines of hippocampus. J Neurosci. 25, 2062-2069. 
Lin C.Y., Lynch G., Gall C.M., 2005b. AMPA receptor stimulation increases alpha5beta1 integrin surface expression, adhesive function and signaling. J Neurochem. 94, 531-546.

Luo J., Phan T.X., Yang Y., Garelick M.G. , Storm D.R., 2013. Increases in cAMP, MAPK activity, and CREB phosphorylation during REM sleep: implications for REM sleep and memory consolidation. J Neurosci. 33, 6460-6468.

Lynch G., Kramar E.A., Babayan A.H., Rumbaugh G., Gall C.M., 2013. Differences between synaptic plasticity thresholds result in new timing rules for maximizing long-term potentiation. Neuropharmacology. 64, 27-36.

Lynch G., Rex C.S., Gall C.M., 2007. LTP consolidation: substrates, explanatory power, and functional significance. Neuropharmacology. 52, 12-23.

Mantzur L., Joels G., Lamprecht R., 2009. Actin polymerization in lateral amygdala is essential for fear memory formation. Neurobiol Learn Mem. 91, 85-88.

Martinez J.L., Jr, Jensen R.A., McGaugh J.L., 1981. Attenuation of experimentally-induced amnesia. Prog. Neurobiol. 16, 155-186.

McGaugh J.L., 2000. Memory--a century of consolidation. Science. 287, 248-251.

McGaugh J.L., 2003. Memory and Emotion: The Making of Lasting Memories. Columbia University Press, New York.

McQuown S.C., Barrett R.M., Matheos D.P., Post R.J., Rogge G.A., Alenghat T., Mullican S.E., Jones S., Rusche J.R., Lazar M.A., Wood M.A., 2011. HDAC3 is a critical negative regulator of long-term memory formation. J Neurosci. 31, 764-774.

Minichiello L., 2009. TrkB signalling pathways in LTP and learning. Nat Rev Neurosci. 10, 850860.

Minichiello L., Korte M., Wolfer D., Kuhn R., Unsicker K., Cestari V., Rossi-Arnaud C., Lipp H.P., Bonhoeffer T., Klein R., 1999. Essential role for TrkB receptors in hippocampus-mediated learning. Neuron. 24, 401-414.

Miyashita T., Kubik S., Lewandowski G., Guzowski J.F., 2008. Networks of neurons, networks of genes: an integrated view of memory consolidation. Neurobiol Learn Mem. 89, 269-284. 
Muller G.E. , Pilzecker A., 1900. Experimentelle Beiträge zur Lehre vom Gedächtnis. Z. Psychol. Ergänzungsband. 1, 1-300.

Nagy V., Bozdagi O., Matynia A., Balcerzyk M., Okulski P., Dzwonek J., Costa R.M., Silva A.J., Kaczmarek L., Huntley G.W., 2006. Matrix metalloproteinase-9 is required for hippocampal late-phase long-term potentiation and memory. J Neurosci. 26, 1923-1934.

Nonaka M., Kim R., Fukushima H., Sasaki K., Suzuki K., Okamura M., Ishii Y., Kawashima T., Kamijo S., Takemoto-Kimura S., Okuno H., Kida S., Bito H., 2014. Region-Specific Activation of CRTC1-CREB Signaling Mediates Long-Term Fear Memory. Neuron. 84, 92-106.

Okamoto K., Bosch M., Hayashi Y., 2009. The roles of CaMKII and F-actin in the structural plasticity of dendritic spines: a potential molecular identity of a synaptic tag? Physiology (Bethesda). 24, 357-366.

Osten P., Hrabetova S., Sacktor T.C., 1996. Differential downregulation of protein kinase C isoforms in spreading depression. Neurosci Lett. 221, 37-40.

Pang P., Teng H., Zaitsev E., Woo N., Sakata K., Zhen S., Teng K., Yung W., Hempstead B., Lu B., 2004. Cleavage of proBDNF by tPA/plasmin is essential for long-term hippocampal plasticity. Science. 306, 487-491.

Park M., Salgado J.M., Ostroff L., Helton T.D., Robinson C.G., Harris K.M., Ehlers M.D., 2006. Plasticity-induced growth of dendritic spines by exocytic trafficking from recycling endosomes. Neuron. 52, 817-830.

Perlmutter L.S., Siman R., Gall C., Seubert P., Baudry M., Lynch G., 1988. The ultrastructural localization of calcium-activated protease 'calpain' in rat brain. Synapse. 2, 79-88.

Pevzner A., Miyashita T., Schiffman A.J., Guzowski J.F., 2012. Temporal dynamics of Arc gene induction in hippocampus: relationship to context memory formation. Neurobiol Learn Mem. 97, 313-320.

Plath N., Ohana O., Dammermann B., Errington M.L., Schmitz D., Gross C., Mao X., Engelsberg A., Mahlke C., Welzl H., Kobalz U., Stawrakakis A., Fernandez E., Waltereit R., BickSander A., Therstappen E., Cooke S.F., Blanquet V., Wurst W., Salmen B., Bosl M.R., 
Lipp H.P., Grant S.G., Bliss T.V., Wolfer D.P., Kuhl D., 2006. Arc/Arg3.1 is essential for the consolidation of synaptic plasticity and memories. Neuron. 52, 437-444.

Ploski J.E., Pierre V.J., Smucny J., Park K., Monsey M.S., Overeem K.A., Schafe G.E., 2008. The activity-regulated cytoskeletal-associated protein (Arc/Arg3.1) is required for memory consolidation of pavlovian fear conditioning in the lateral amygdala. J Neurosci. 28, 1238312395.

Ramachandran B., Frey J.U., 2009. Interfering with the actin network and its effect on long-term potentiation and synaptic tagging in hippocampal CA1 neurons in slices in vitro. J Neurosci. 29, 12167-12173.

Raymond C.R., Thompson V.L., Tate W.P., Abraham W.C., 2000. Metabotropic glutamate receptors trigger homosynaptic protein synthesis to prolong long-term potentiation. J Neurosci. 20, 969-976.

Redondo R.L., Okuno H., Spooner P.A., Frenguelli B.G., Bito H., Morris R.G., 2010. Synaptic tagging and capture: differential role of distinct calcium/calmodulin kinases in protein synthesis-dependent long-term potentiation. J Neurosci. 30, 4981-4989.

Rehberg K., Bergado-Acosta J.R., Koch J.C., Stork O., 2010. Disruption of fear memory consolidation and reconsolidation by actin filament arrest in the basolateral amygdala. Neurobiol Learn Mem. 94, 117-126.

Rex C.S., Chen L.Y., Sharma A., Liu J., Babayan A.H., Gall C.M., Lynch G., 2009. Different Rho GTPase-dependent signaling pathways initiate sequential steps in the consolidation of long-term potentiation. J Cell Biol. 186, 85-97.

Rex C.S., Gavin C.F., Rubio M.D., Kramar E.A., Chen L.Y., Jia Y., Huganir R.L., Muzyczka N., Gall C.M., Miller C.A., Lynch G., Rumbaugh G., 2010. Myosin Ilb regulates actin dynamics during synaptic plasticity and memory formation. Neuron. 67, 603-617.

Rex C.S., Lin C.Y., Kramar E.A., Chen L.Y., Gall C.M., Lynch G., 2007. Brain-derived neurotrophic factor promotes long-term potentiation-related cytoskeletal changes in adult hippocampus. J Neurosci. 27, 3017-3029.

Ribot T. (1882). Diseases of Memory. Apppleton-Century-Crofts, New York. 
Robles Y., Vivas-Mejia P.E., Ortiz-Zuazaga H.G., Felix J., Ramos X., Pena de Ortiz S., 2003. Hippocampal gene expression profiling in spatial discrimination learning. Neurobiol Learn Mem. 80, 80-95.

Routtenberg A., Rekart J.L., 2005. Post-translational protein modification as the substrate for long-lasting memory. Trends Neurosci. 28, 12-19.

Rudy J.W., 2008. Is there a baby in the bathwater? Maybe: some methodological issues for the de novo protein synthesis hypothesis. Neurobiol Learn Mem. 89, 219-224.

Sacktor T.C., 2008. PKMzeta, LTP maintenance, and the dynamic molecular biology of memory storage. Prog Brain Res. 169, 27-40.

Sajikumar S., Navakkode S., Frey J.U., 2007. Identification of compartment- and processspecific molecules required for "synaptic tagging" during long-term potentiation and longterm depression in hippocampal CA1. J Neurosci. 27, 5068-5080.

Sharma A.V., Nargang F.E., Dickson C.T., 2012. Neurosilence: profound suppression of neural activity following intracerebral administration of the protein synthesis inhibitor anisomycin. J Neurosci. 32, 2377-2387.

Squire L.R., Barondes S.H., 1970. Actinomycin-D: effects on memory at different times after training. Nature. 225, 649-650.

Staubli U., Faraday R., Lynch G., 1985. Pharmacological dissociation of memory: anisomycin, a protein synthesis inhibitor, and leupeptin, a protease inhibitor, block different learning tasks. Behav Neural Biol. 43, 287-297.

Steward O. Worley P., 2002. Local synthesis of proteins at synaptic sites on dendrites: role in synaptic plasticity and memory consolidation? Neurobiol Learn Mem. 78, 508-527.

Tao X., Finkbeiner S., Arnold D.B., Shaywitz A.J., Greenberg M.E., 1998. Ca2+ influx regulates BDNF transcription by a CREB family transcription factor-dependent mechanism. Neuron. 20, 709-726.

Taubenfeld S.M., Milekic M.H., Monti B., Alberini C.M., 2001. The consolidation of new but not reactivated memory requires hippocampal C/EBPbeta. Nat Neurosci. 4, 813-818. 
Taubenfeld S.M., Stevens K.A., Pollonini G., Ruggiero J., Alberini C.M., 2002. Profound molecular changes following hippocampal slice preparation: loss of AMPA receptor subunits and uncoupled mRNA/protein expression. J Neurochem. 81, 1348-1360.

Tsokas P., Grace E.A., Chan P., Ma T., Sealfon S.C., Iyengar R., Landau E.M., Blitzer R.D., 2005. Local protein synthesis mediates a rapid increase in dendritic elongation factor $1 \mathrm{~A}$ after induction of late long-term potentiation. J Neurosci. 25, 5833-5843.

Vanderklish P., Saido T.C., Gall C., Arai A., Lynch G., 1995. Proteolysis of spectrin by calpain accompanies theta-burst stimulation in cultured hippocampal slices. Mol. Brain Res. 32, 25-35.

Vanderklish P.W., Krushel L.A., Holst B.H., Gally J.A., Crossin K.L., Edelman G.M., 2000. Marking synaptic activity in dendritic spines with a calpain substrate exhibiting fluorescence resonance energy transfer. Proc. Natl. Acad. Sci. USA. 97, 2253-2258.

Villers A., Godaux E. Ris L., 2012. Long-lasting LTP requires neither repeated trains for its induction nor protein synthesis for its development. PLoS One. 7, e40823.

Wang X.B., Bozdagi O., Nikitczuk J.S., Zhai Z.W., Zhou Q., Huntley G.W., 2008. Extracellular proteolysis by matrix metalloproteinase- 9 drives dendritic spine enlargement and longterm potentiation coordinately. Proc Natl Acad Sci U S A. 105, 19520-19525.

Zhou Q., Abe H., Nowak T.S., Jr., 1995. Immunocytochemical and in situ hybridization approaches to the optimization of brain slice preparations. J Neurosci Methods. 59, 85-92. 


\section{Figure Captions.}

Figure 1. Theta burst stimulation (TBS) promotes actin polymerization and cofilin phosphorylation in adult hippocampal slices. Images were collected from proximal CA1b stratum radiatum following stimulation of Schaffer/commissural afferents. (A,B) In situ phalloidin labeling in slices that received $(\mathrm{A})$ baseline low-frequency stimulation (LFS) or (B) TBS illustrates the increase in F-actin enriched spines (dark puncta) achieved with theta stimulation. (C) Deconvolved epifluorescence images show immunolabeling for phosphorylated (p) Cofilin, and excitatory synapse scaffold protein PSD95, and the merged image of the two for the same field; arrowheads indicate double-labeled synapses. Cofilin is downstream effector of RhoA: phosphorylation inactivates this F-actin severing protein thus allowing actin polymers to survive and elongate. Quantification of spine labeling (bar graph, right) shows that TBS transiently increases numbers of pCofilin+ enriched contacts indicating transient cofilin inactivation (mean \pm SEM values for $8-9$ slices/group; ${ }^{* *} p=0.008$ vs controls). Scale bars $5 \mu \mathrm{m}$ (in B for A and B). Modified from Baudry, et al., 2012 and Chen et al., 2007.

Figure 2. Protein synthesis inhibition does not block theta burst induced LTP. Adult hippocampal slices prepared and placed in an interface chamber with as described (Kramar et al., 2012): two stimulation electrodes were used to drive separate but convergent populations (paths) of Schaffer/commissural afferents to the CA1b field of recording. In all experiments slices were allowed to equilibrate in the interface chamber, with constantly perfusing ACSF, for $1.5 \mathrm{hr}$ prior to testing. Following $20 \mathrm{~min}$ of stable baseline recording, $40 \mu \mathrm{M}$ anisomycin (ANIS) (A) or $20 \mu \mathrm{M}$ emetine (B) was infused 
into the slice bath, 30 min prior to application of a single train of theta burst stimulation (TBS, arrow) to the 'experimental path', and continued for 30 minutes afterwards. Following at least 60 min washout of the inhibitor, a second TBS train was applied to the 'control' path. As shown, neither anisomycin (A) or emetine (B) disrupted stable LTP in the experimental (inhibitor present) or control (inhibitor washout) path.

Figure 3. A protein synthesis inhibition blocks LTP in 'mature' slices. (A) Stable baseline recordings of Schaffer-commissural fEPSPs were collected from CA1b stratum radiatum for $4.5 \mathrm{hr}$ before applying ANIS to the slice bath 30 min prior to TBS (6 hours after slice preparation). Under these conditions, TBS of the 'experimental' path (orange symbols) induced an initial potentiation but the fEPSP slope gradually returned to baseline levels over a 1 hour recording period. LTP induced $4.5 \mathrm{hrs}$ earlier in a separate population of axons ('control path') was unaffected by the inhibitor. (B) In a separate set of slices, baseline recordings were collected for 4.5 prior to delivery of TBS (6 hours after cutting) in the absence of the inhibitor. Robust LTP was obtained and remained stable during the $3 \mathrm{hr}$ post-TBS recording session.

Figure 4. Incubation with anisomycin during slice preparation and through delivery of TBS fails to block LTP. Adult rat hippocampal slices were sectioned in the presence of $40 \mu \mathrm{M}$ anisomycin and then continuously treated with inhibitor or vehicle (0.01\% DMSO) in ACSF for the following 2.5 hours. After $2 \mathrm{hr}$ of incubation and 20 min of stable baseline recording, TBS was applied to Schaffer/commissural afferents of CA1b stratum radiatum where fEPSPs were recorded. As shown, potentiation was ro- 
bust, stable, and of comparable magnitude in slices incubated in anisomycin or vehicle. Note that the inhibitor incubation time for this study was much longer than that employed in the studies described in Fig 3A.

Figure 5. Prior induction of LTP in one pathway in mature slices greatly reduces the disruptive effects of anisomycin on LTP in a second input. Following a $5 \mathrm{hr}$ incubation in an interface chamber with constant normal ACSF perfusion, LTP was induced by TBS in one pathway ('control path') and potentiation of the fEPSP slope was recorded for the remainder of the experiment. Anisomycin $(40 \mu \mathrm{M})$ was introduced into the bath (horizontal bar) prior to delivery of TBS to a second input ('experimental path') to the same dendritic field. The first LTP episode blocked the marked disruptive effects of anisomycin seen in the earlier study (Fig 3A) using mature ( $\sim 6 \mathrm{hr}$ ) slices.

Figure 6. Integrin dynamics generate a delayed, second stage of consolidation for LTP and memory. (A) Immunoreactivity for the activated form of $ß 1$ family integrins (Act-ß1) at synapses was significantly increased relative to controls two minutes following TBS (orange bar). In separate experiments, a second theta burst train (TBS2, blue bars) was delivered to the same synapses at different time points after TBS1 and the slices immunostained for activated- $\beta 1$ integrin at synapses. Note that TBS2 effectively increased Act-ß1 only after a 60 min delay following TBS1. (B) Local application of neutralizing antisera against B1 integrins, starting 30 min after TBS1, caused a gradual decay of LTP while the control antibody (anti-IgG) did not. Inset; representative traces collected before (black) and $90 \mathrm{~min}$ after (red) TBS1. Scale bar $=1 \mathrm{mV}, 5 \mathrm{~ms}$. (C) Local 
perfusion of neutralizing anti- $\beta 1$ starting 60 min after delivery of TBS failed to disrupt LTP consolidation. (D) Object location memory scores ('discrimination index') on day 2 of testing for mice that received intrahippocampal infusion of neutralizing anti- $\beta 1$ integrin at 5,20 , or 60 min after training on day one. Infusions at 5 or 20 min blocked long term memory while those starting 60 min post-training did not. Anti-IgG infusion had no statistical effect at any time point. (E) Bar graph shows grouped data (quantification of Act$\beta 1+$ synapses) from slices that were perfused with brefeldin A (bref., $35 \mu \mathrm{M}$ ) for 40 min prior to delivery of TBS1 and collected 2 min afterwards (orange bar). The toxin had no detectable effect on integrin activation (compare to panel A). The same treatment applied before TBS2 blocked integrin activation (blue bar). (F) Plot shows that perfusion of brefeldin-A starting 10 min after TBS1 caused a gradual decay in field EPSP slope (i.e., a loss of potentiation) similar to effects of anti-ß1. (G) Using the same procedure as in E, perfusion of anisomycin (anis., $10 \mu \mathrm{M}$ ) failed to block activated-ß1 following TBS1 or TBS2. Modified from Babayan et al., 2012. 

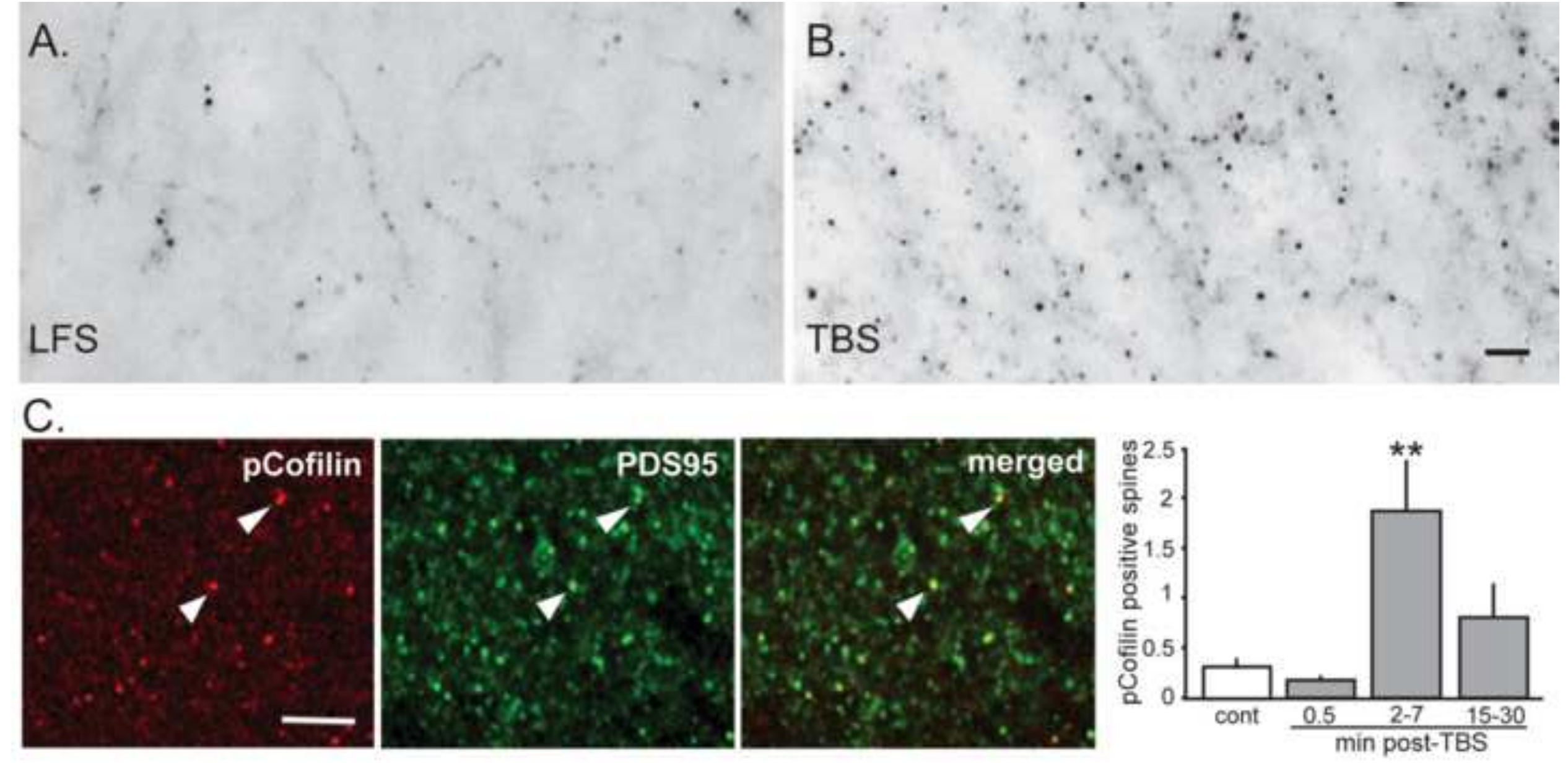
A.

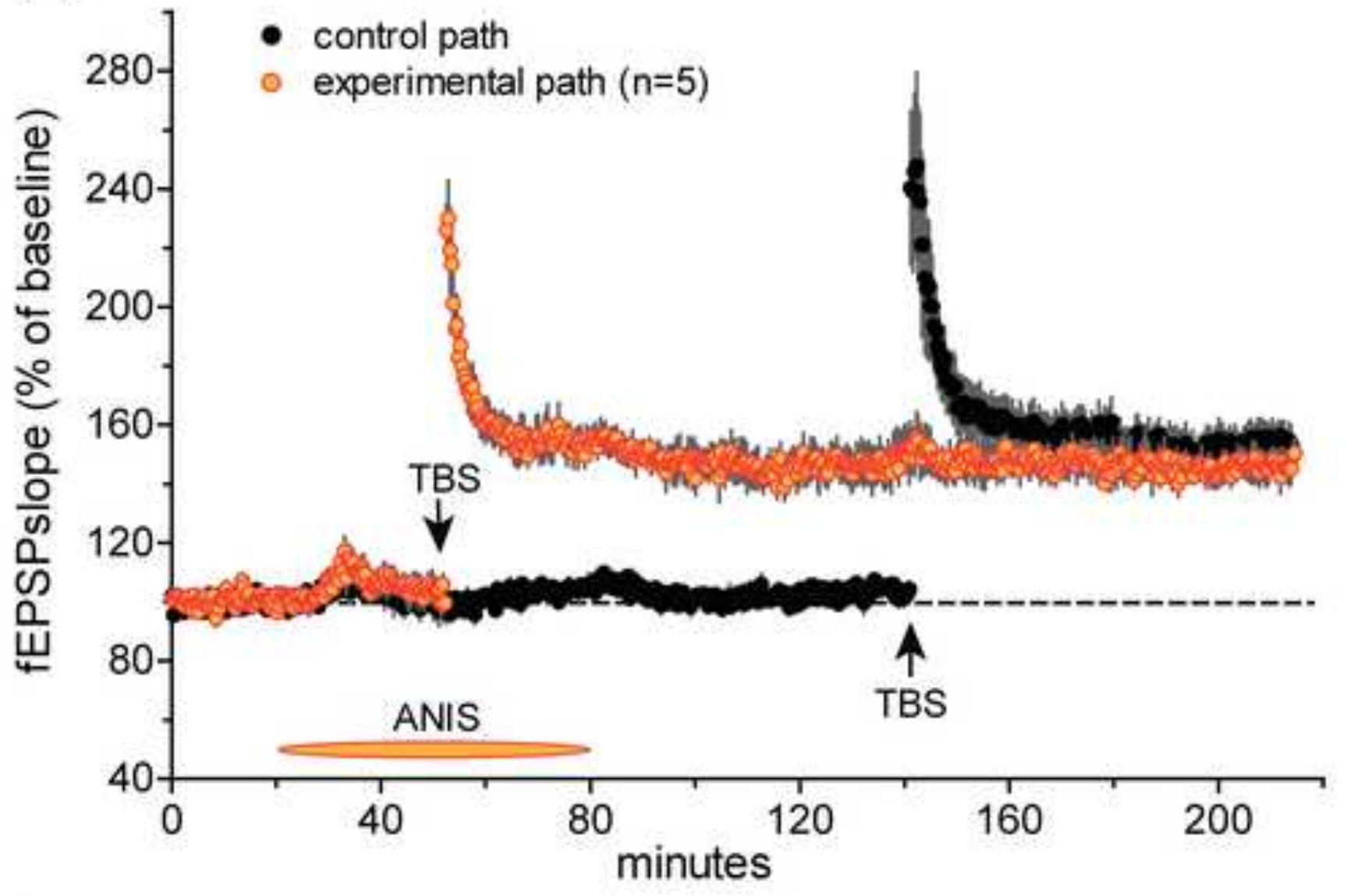

B.

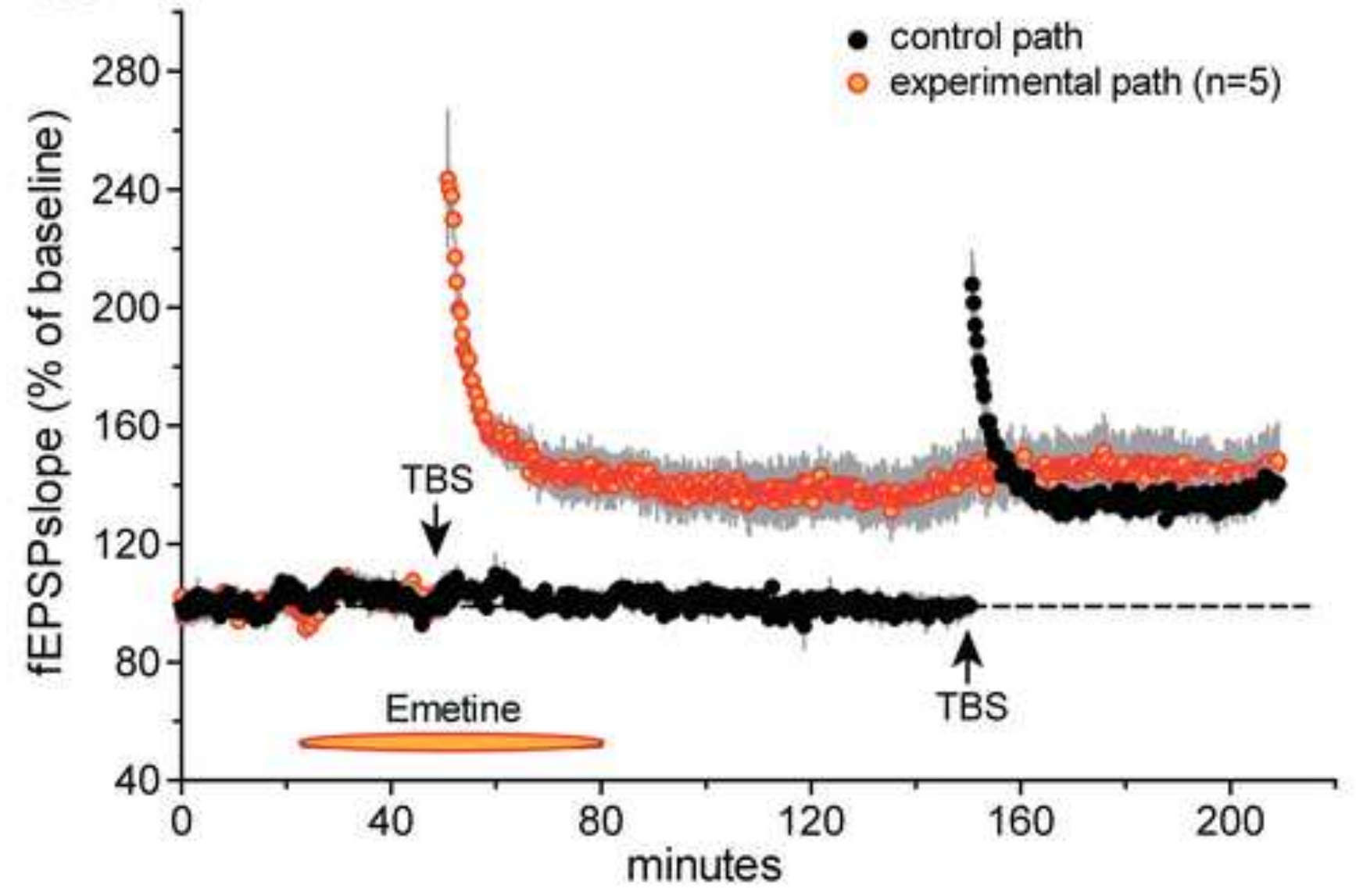


A.

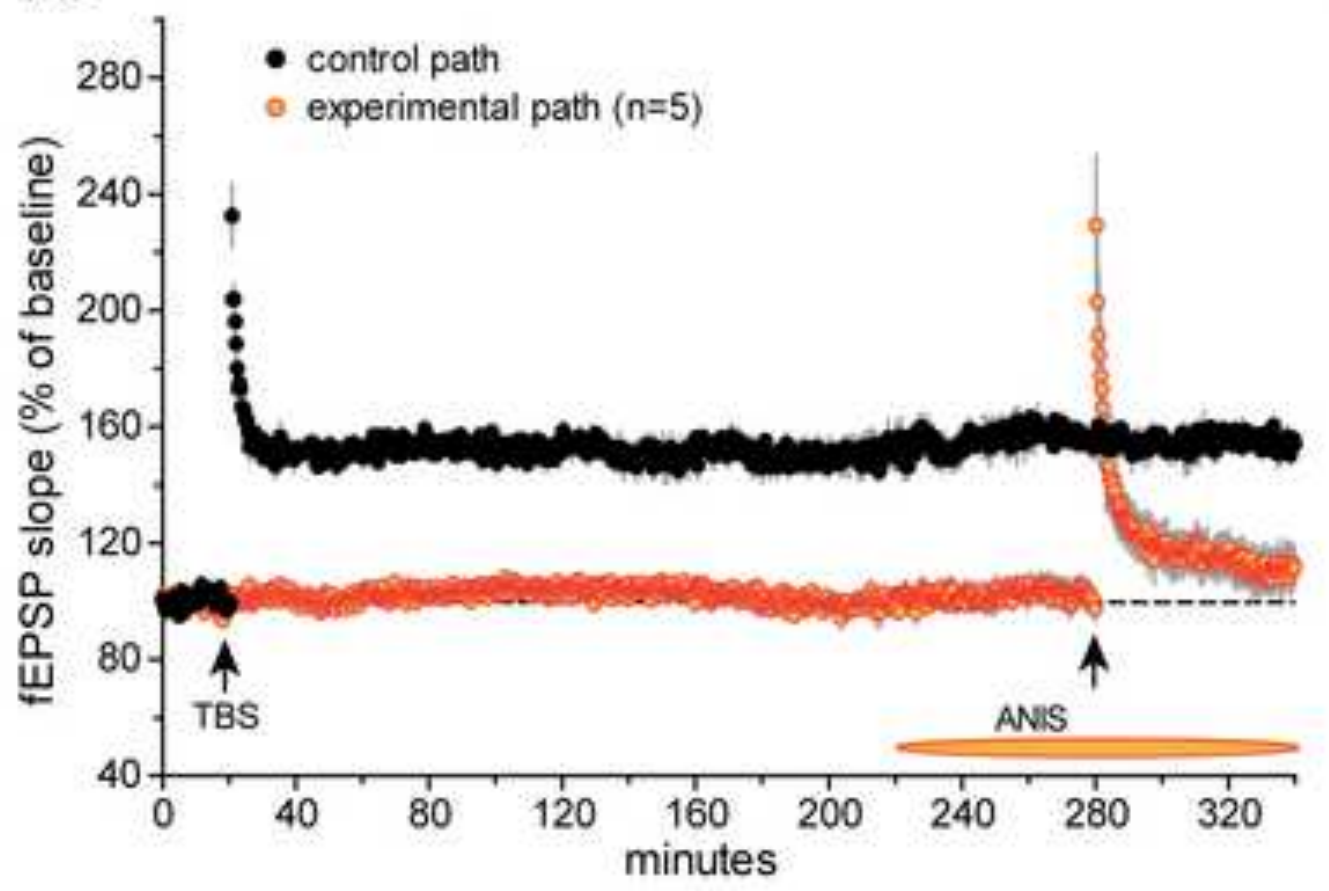

B.

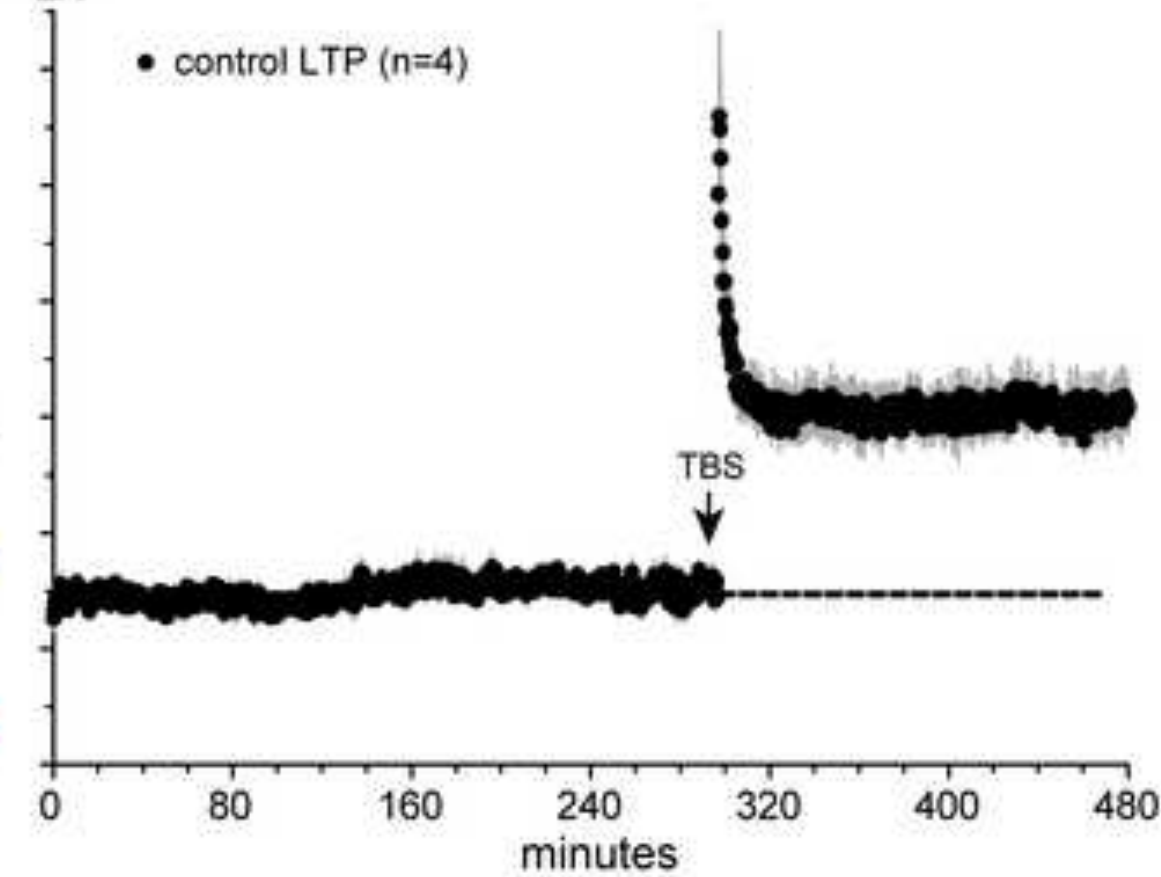




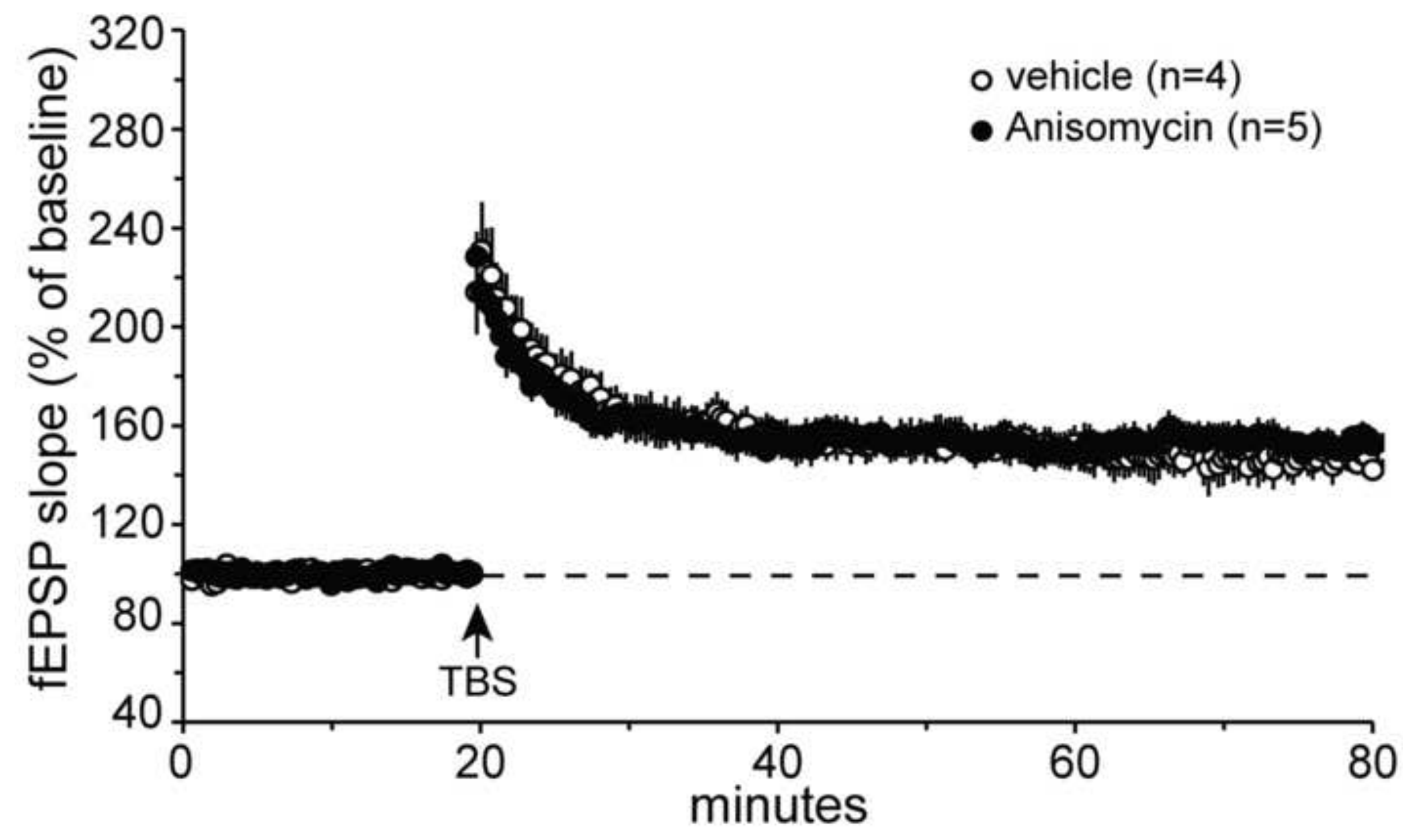




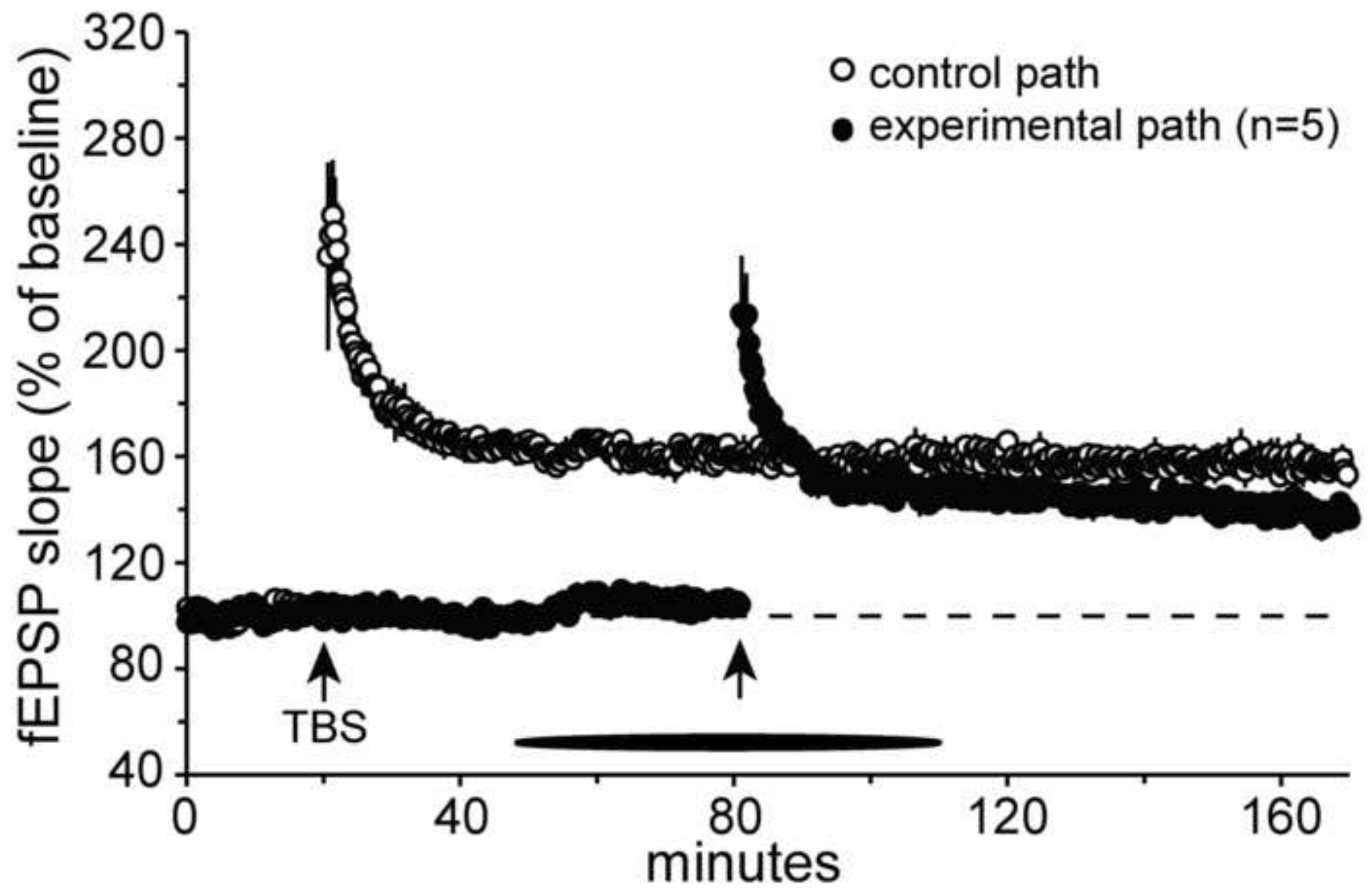




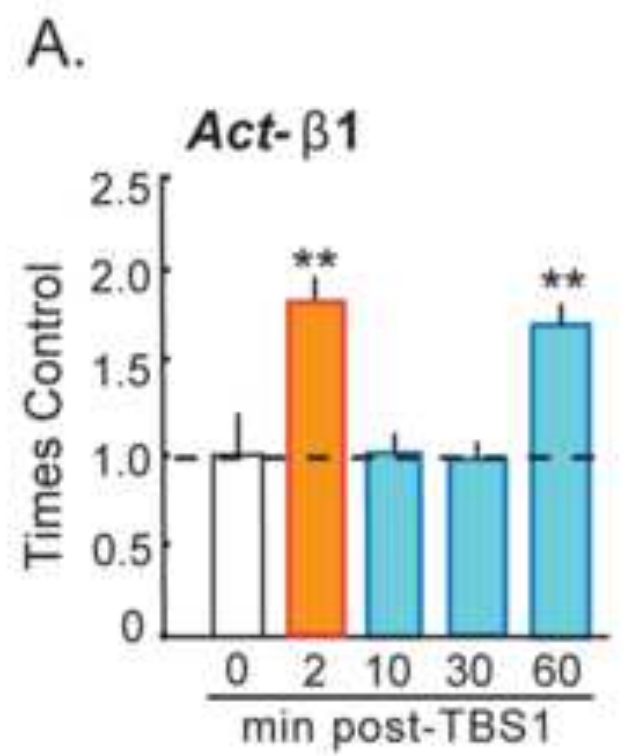

C.

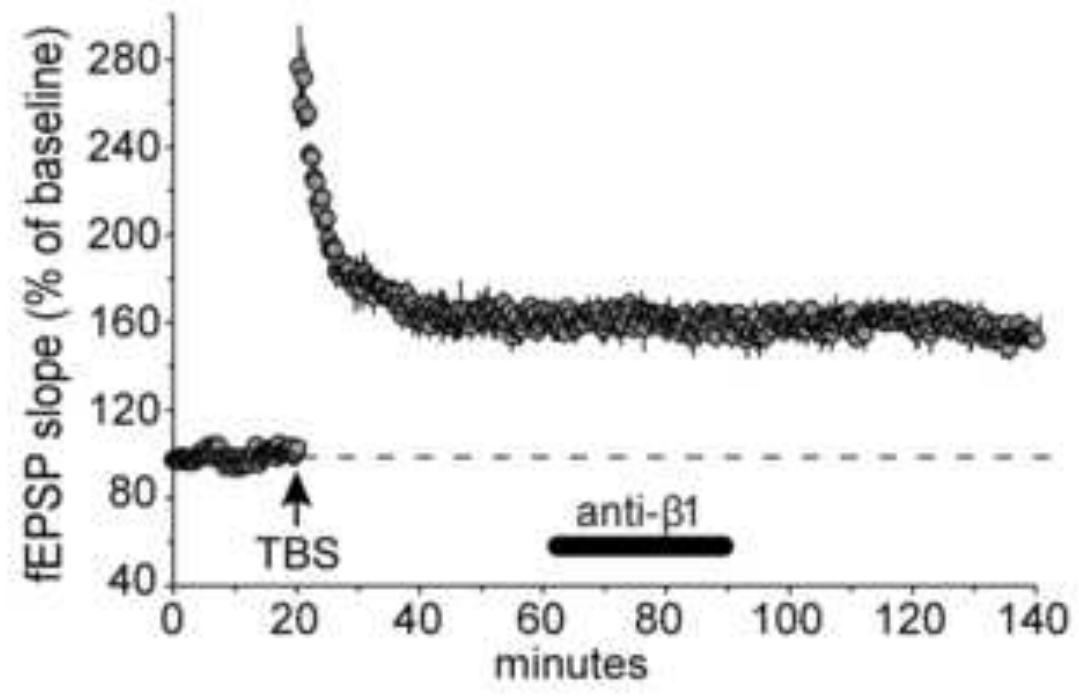

E.

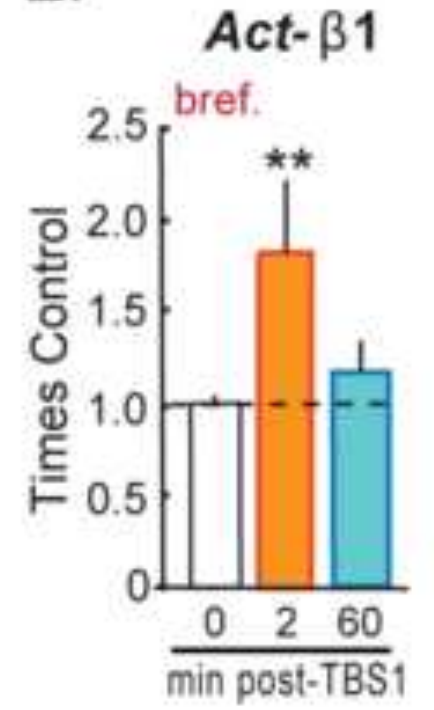

B.

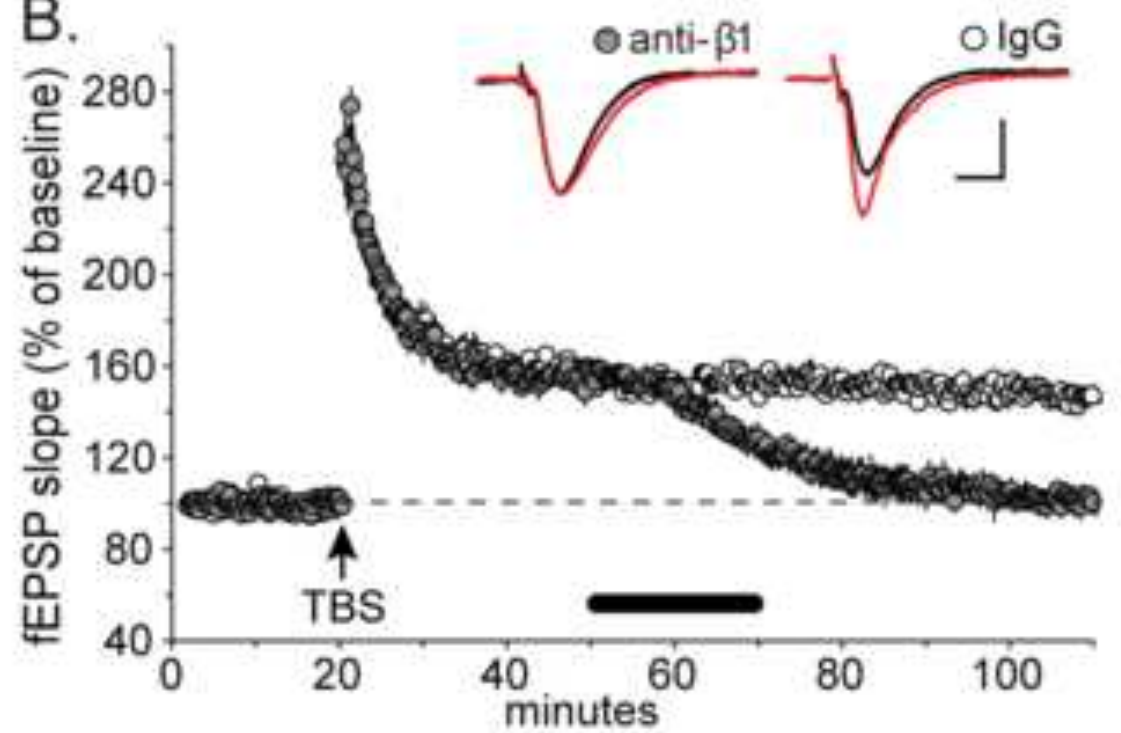

D. $\square \operatorname{lgg} \square$ anti- $\beta 1$

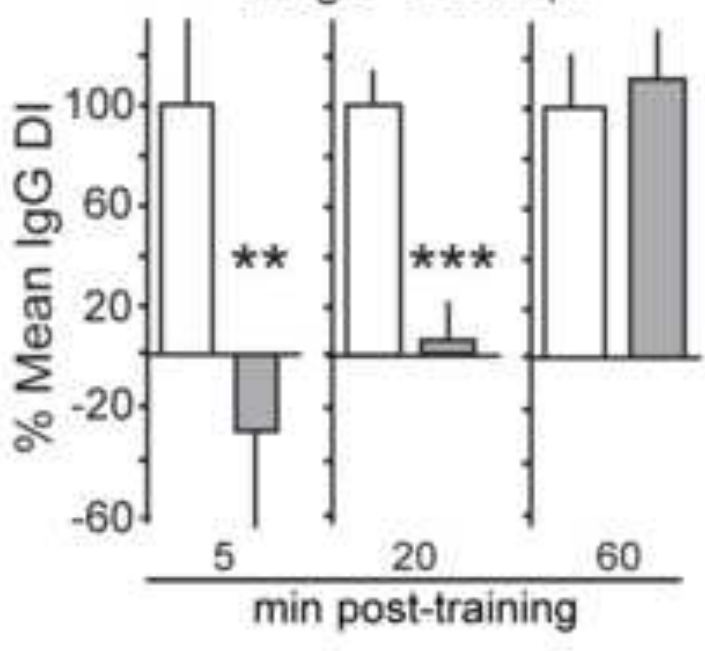

G.

Act- $\beta 1$

- control path

- experimental path

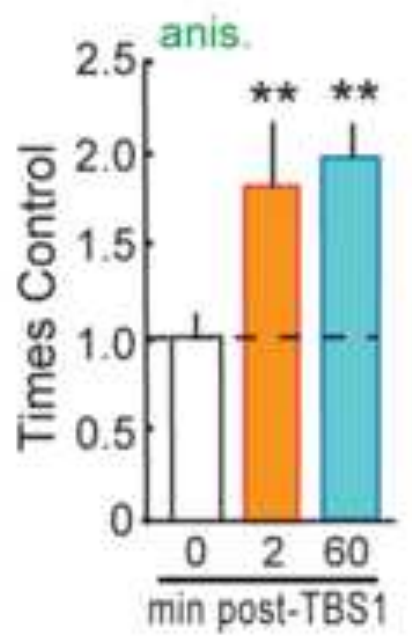

